\title{
INFLUÊNCIA DO ENOS E AMO ENTRE 2003-2014 NO CLIMA E REGIMES DE FOGO NA GRAN SABANA, PARQUE NACIONAL CANAIMA, GUIANA VENEZUELANA
}

\author{
SALAZAR-GÁSCON, Ruth Estefania - ruth120488@gmail.com \\ Universidade Federal de Juiz de Fora / UFJF
}

FERREIRA, Cassia de Castro Martins - cassia.castro@ufjf.edu.br

Universidade Federal de Juiz de Fora / UFJF

\begin{abstract}
RESUMO: O objetivo do trabalho foi avaliar a frequência e severidade das queimadas que aconteceram na Gran Sabana (GS) de 2003 a 2014 em relação: aos eventos climáticos extremos como ENOS (EI Niño-La Niña/Oscilação do Sul) e AMO (Oscilação Multidecadal do Atlântico-Tropical norte) e às dinâmicas da vegetação na GS. Foram usados dados de focos de queimadas, pluviosidade, anomalias nas Temperaturas da Superfície do Mar (TSM) no Oceano Pacífico e Atlântico e Imagens de satélites. Estimaram-se: correlações de Pearson ( $r$ ) entre: as frequências de queimadas VS as anomalias nas TSM e pluviosidade VS anomalias nas TSM; Índice Normalizado de Queimadas (INQ); Índice de Vegetação por Diferencia Normalizado (NDVI); frequência e extensão de cicatrizes de queimadas; e mudanças na cobertura dos solos. Obteve-se que: AMO+ afeta a localização da ZCIT e altera a Célula de Hadley incrementando as precipitações na GS; anomalias El Niño (La Niña) alteram a Célula de Walker, promovendo a pluviosidade e diminuição na extensão dos períodos de secas; La Niña e $\mathrm{AMO}+$ quando atuam em sincronia geram grandes volumes de precipitação; El Niño e $\mathrm{AMO}+$ quando acontecem em sincronia diminuem o efeito do El Niño; secas prolongadas contribuem em: degradação dos sistemas arbóreos, expansão dos sistemas herbáceos e no aumento da frequência de queimadas; AMO e/ou La Niña contribuem na expansão dos sistemas arbustivos, e em menor grau a recuperação dos sistemas arbóreos; as distribuições das cicatrizes de queimadas se encontram associadas às mudanças nos padrões culturais de subsistência das populacionais locais. Conclui-se que a severidade e frequências das queimadas na GS são um processo multifatorial e multiescalar que acontecem como produto da sincronia de fatores ecossistêmicos (vegetação), sociais (proximidade aos centros populacionais) e climáticos (ENOS e AMO).
\end{abstract}

PALAVRAS-CHAVES: Parque Nacional Canaima, Queimadas, ENOS, AMO; Guiana Venezuelana.

INFLUENCIA DE ENOS Y AMO ENTRE 2003-2014 EN EL CLIMA Y REGÍMES DE FUEGO EN GRAN SABANA, PARQUE NACIONAL CANAIMA, GUIANA VENEZUELANA

RESUMEN: El objetivo fue evaluar la frecuencia y severidad de los incendios que se produjeron en la Gran Sabana (GS) entre 2003 y 2014 en relación: a fenómenos climáticos extremos tales como ENOS (El Niño-La Niña / Oscilación del Sur) y OMA (Oscilación Multidecadal del Atlántico- tropical norte), y la dinámica de la vegetación en la GS. Se utilizaron los datos de focos de incendios, de precipitación, anomalías en las temperaturas de la superficie del mar (TSM) en el Océano Pacífico y el Atlántico, e imágenes de satélite. Fueron estimados: correlaciones de Pearson ( $r$ ) entre: la frecuencia de los incendios VS anomalías en TSM y en precipitación VS anomalías de TSM; Índice normalizado de incendios (INQ); Índice de vegetación normalizado (NDVI); frecuencia y extensión de las cicatrices de incendios; y los cambios en la cobertura del suelo. Se obtuvo que: AMO+ afecta el posicionamiento de la ZCIT y cambia la célula de Hadley aumentando las precipitaciones en la GS; anomalía El Niño (La Niña) altera la célula Walker, inhibiendo (promoviendo) la precipitación y el aumento (disminución) de la duración de las sequías; La Niña y AMO+ cuando operan en sincronía generan grandes volúmenes de precipitación; El Niño y $\mathrm{AMO}+$ cuando se producen sincrónicamente 
disminuyen el efecto de El Niño; sequías prolongadas contribuyen: degradación de los sistemas arbóreos, la expansión de los sistemas de herbáceas y el aumento de la frecuencia de los incendios; AMO+ y/o La Niña contribuyen a la expansión de los sistemas de arbustos, y en menor medida la recuperación de los sistemas arbóreos; distribuciones de cicatrices incendios están asociados con los cambios en los patrones culturales de subsistencia de la población local. Se concluye que la severidad y frecuencia de los incendios en la GS son un proceso multifactorial y multiescalar que ocurre como consecuencia de la sincronización de factores ecosistémicos (vegetación), sociales (proximidad a centros de población) y climáticos (ENOS y AMO).

PALABRAS ClAVE: Parque Nacional Canaima, incendios, ENOS, AMO; Guayana venezolana.

\section{INFLUENCE OF ENSO AND AMO AMONG 2003-2014 IN CLIMATE AND FIRE REGIMES IN GRAN SABANA, CANAIMA NATIONAL PARK, GUIANA VENEZUELANA}

ABSTRACT: The objective was to evaluate the frequency and severity of fires that occurred in the Gran Sabana (GS) between 2003 and 2014 in relation: to extreme climate events such as ENSO (EI Niño-La Niña / Southern Oscillation) and OMA (Oscillation Multidecadal the Tropical Atlantic-north), and vegetation dynamics in the GS. Data sources of fire, precipitation, anomalies in surface temperatures (SSTs) in the Pacific and the Atlantic Ocean, and satellite images were used. They were estimated: Pearson correlations ( $r$ ) between: the frequency of fires VS SST anomalies and precipitation VS SST anomalies; Fire normalized ratio (INQ); Normalized Difference Vegetation Index (NDVI); frequency and extent of fire scars; and changes in land cover. It was found that: AMO + affects the positioning of the ITCZ and the Hadley cell changes increasing precipitation in the GS; anomaly El Niño (La Niña) alters the Walker cell, inhibiting (promoting) precipitation and increase (decrease) in the duration of droughts; La Niña and AMO + when operating in synchrony generate large volumes of precipitation; El Niño and AMO + when they occur synchronously decrease the effect of El Niño; prolonged droughts contribute: degradation of tree systems, expansion of herbaceous systems and increased frequency of fires; AMO + and/or La Niña contribute to the expansion of bushes systems, and to a lesser extent the recovery of tree systems; distributions fire scars are associated with changes in cultural patterns of livelihood of the local population. It is concluded that the severity and frequency of fires in the GS is a multifactorial and multiscale process that occurs as a result of the timing factors of ecosystem (vegetation), social (proximity to population centers) and climatic (ENSO and AMO).

KEYWORDS: Canaima National Park, Fires, ENSO, AMO; Venezuelan Guayana

INFLUENCE DE L'ENSO ET DE L'AMO DE 2003 À 2014 SUR LES RÉGIMES CLIMATIQUES ET D'INCENDIE DE LA GRAN SABANA, PARC NATIONAL CANAIMA, GUIANA VENEZUELANA

RESUME: L'objectif était d'évaluer la fréquence et la gravité des incendies qui se sont produits dans la Gran Sabana (GS) entre 2003 et 2014 en ce qui concerne: les événements climatiques extrêmes tels que ENSO (EI Niño-La Niña / Southern Oscillation) et OMA (Oscillation Multidecadal I'Atlantique-nord tropical), et la dynamique de la végétation dans la GS. Sources de feu de données, de précipitations, les anomalies dans les températures de surface (TSM) dans l'océan Pacifique et l'Atlantique, et les images satellites ont été utilisés. Ils ont été estimés: corrélations de Pearson ( $r$ ) entre: la fréquence des incendies VS anomalies de SST et précipitations VS anomalies de SST; Feu rapport normalisé (INQ); Normalized Difference Vegetation Index (NDVI); la fréquence et l'étendue des cicatrices de feu; et les changements de la couverture terrestre. Il a été constaté que: AMO + affecte le positionnement de la ZCIT et les changements cellulaires Hadley augmentation des précipitations dans les GS; anomalie El Niño (La Niña) modifie la cellule Walker, inhibant (promotion) précipitations et augmentation (diminution) de la durée des sécheresses; La Niña et AMO + lors du fonctionnement en synchronie générer de gros volumes de précipitations; Enfants et AMO + quand ils se produisent de façon 
synchrone diminuer l'effet d'El Niño; sécheresses prolongées contribuent: la dégradation des systèmes d'arbres, l'expansion des systèmes d'herbacées et la fréquence accrue des incendies; $\mathrm{AMO}+$ et/ou Niña contribuent au développement des systèmes de douilles, et dans une moindre mesure, la récupération des systèmes d'arbres; cicatrices distributions d'incendie sont associés à des changements dans les habitudes culturelles de subsistance de la population locale. Il est conclu que la gravité et la fréquence des incendies dans la GS est un processus multifactoriel et multiéchelle qui se produit en raison du calendrier des facteurs écosystémiques (végétation), sociale (proximité des centres de population) et climatiques (ENSO et AMO).

MOT CLÉS: Parc national Canaima, Incendies, ENSO, AMO; Guayana vénézuélienne.

\section{INTRODUÇÃO}

O Parque Nacional Canaima (PNC), criado em junho de 1962, encontrase localizado no Alto Caroní, ao sudeste da Venezuela, e possui uma importância econômica e estratégica, já que dentro de seus limites estão as nascentes dos rios que abastecem a Bacia do Rio Caroní, onde está instalada a central hidroelétrica Simón Bolívar, que fornece $72 \%$ da energia hidroelétrica nacional (EDELCA, 2008). O PNC foi reconhecido como patrimônio mundial da humanidade pela UNESCO em 1994 por ser uma região que representa as maiores estágios da história da evolução da terra; os processos geológicos e biológicos atuais na evolução e desenvolvimento dos ecossistemas terrestres, aquáticos e das comunidade de plantas e animais; a presença de fenômenos naturais superlativos, raros e únicos, bem como características e áreas de excepcional beleza; ser o habitat aonde sobrevivem populações de espécies de plantas e animais raros ou em perigo de extinção (TORRES e MARTIN, 2007).

Dentro do PNC está localizada a "Gran Sabana" (GS), formada pelos mosaicos de vegetação compostos de florestas de montanha, savanas e arbustos submesotérmicos, com florística complexa e zonas de transição. Savanas dominadas pelas gramíneas e ciperáceas são predominantes e ocupam maior área na GS, enquanto que florestas ribeirinhas e de terra-firme são distribuídas em forma de manchas (HUBER, 1986; HUBER, 1995; HUBER et al., 2001). Toda a área possui um clima predominante tropical chuvoso com precipitações que variam de 1.800 a $2.500 \mathrm{~mm}$ por ano, volume de chuvas normalmente atrelado a áreas com cobertura florestal contínua como apontam Huber et al. (2001). Alguns pesquisadores afirmam que o origem da GS sem a presença de árvores, localizada em uma área úmida, é antropogênica baseada num regime de queimadas contínuas (CHRISTOFFEL, 1939; DEZZEO et al., 2004). Esta hipótese é destacada, por não ter registros de incêndios causados pelos fatores naturais na contemporaneidade, pois os relâmpagos não são considerados uma importante causa de incêndios nos trópicos, já que as trovoadas ocorrem principalmente durante a estação chuvosa.

Bilbao et al. (2010) afirmam que as comunidades indígenas da etnia Pemón, que lá residem há muitos anos desenvolveram um complexo sistema de queimadas nas áreas de savana, que envolve a queima de pequenas manchas, produzindo um mosaico de savana com manchas em diferentes estágios de sucessão. Esse processo é agravado pela alta frequência de fogo na região (2000-3000 incêndios anuais), que queimam uma área de 5.700 - 7.500 ha (GÓMEZ et al., 2000; ABLAN et al., 2005). O que pode produzir um processo de savanização e/ou degradação, associado à vegetação florestal com o consequente aumento das savanas (HUBER et al., 2001). Bilbao et al. (2010) destacam que $70 \%$ dos incêndios detectados começam em áreas cobertas por 
savanas e se alastram para a fronteira entre savana e floresta, causando degradação florestal, como as queimadas periódicas da savana são provocadas por ação antrópica, estas podem invadir áreas de florestas, resultando em uma retração delas, principalmente em anos mais secos. Desta forma, a cobertura vegetal desta região poderia ser considerada como uma fase de transição, em um longo processo de savanização, originalmente produzida por incêndios e condicionada pela baixa resistência da floresta.

Porém, Rodriguez (2004, 2007) afirma que esta hipótese nos fornece uma visão de curto prazo da dinâmica savana/floresta na GS e que a investigação científica apoiou a visão parcial do fogo como componente prejudicial na constituição da vegetação no PNC. Pois na região se encontram também savanas de longa data, como se evidencia nos estudos palinológicos desenvolvidos por Leal (2010) e Rull (1992, 1999). Segundo Edén (1974) e Rull (2004), as savanas podem ser relictas de períodos áridos ocorridos durante o Pleistoceno contemporâneo com as Glaciações do Hemisfério Norte, a qual também é apoiada por Shubert et al. (1986) e Briceño e Shubert (1990). Rull (1992) destaca que a exclusão de elementos arbóreos durante o Holoceno médio é consequência de mudanças climáticas, especificamente mudanças na relação precipitação/evapotranspiração.

Assim a ideia da conversão de florestas por causa de fogo em savanas é de um período mais recente, e atribui ao homem como principal (e único) gerador de incêndios na área pelas atividades de subsistência (RODRIGUEZ, 2004; DEZZEO et al., 2004; RODRIGUEZ; SLETTO, 2009; LEAL, 2010). No entanto, Leal (2010) afirma que, tanto o processo de degradação de florestas, como o processo de desertificação das savanas, produto das queimadas produzidas pelas comunidades locais, não conseguem explicar a ocorrência da Gran Sabana.

Por outro lado, nas últimas décadas tem-se registrado um aumento na frequência dos eventos ENOS (El Niño, Oscilação do Sul e La Niña) e AMO (Oscilação Multidecadal do Atlântico), fato que poderia influenciar na quantidade e intensidade dos incêndios no PNC, já que os períodos de secas geram uma retroalimentação positiva ao potencializar o processo dos incêndios (FEARNSIDE, 2006). Existem principalmente três eventos climáticos responsáveis pela variação na dinâmica e regime de precipitações da região, sendo estes ENOS e AMO. O ENOS que conjuga os eventos El Niño/La Niña e a Oscilação do Sul, se referem às anomalias nas temperaturas superficiais médias do oceano e atmosfera no Pacífico equatorial, enquanto o AMO é o ciclo de aquecimento superficial das águas do Atlântico Tropical Norte (NOBRE et al., 2013).

El Niño ou ENOS em sua fase positiva vem acompanhado do enfraquecimento na intensidade dos ventos alísios do nordeste, influenciando assim a célula de Walker do Pacífico equatorial, provocando um deslocamento das zonas de subsidência, produto de uma inversão no campo de pressão do Pacífico central, que desloca o ramo descendente da célula de Walker sobre a Amazônia, inibindo a formação de nuvens nas atividades convectivas (FISCH et al., 1998, CÁRDENAS et al., 2002; POVEDA et al., 2006; LIMA et al., 2013).

O AMO por sua parte gera perturbações na célula de Hadley, diminuindo a intensidade dos ventos alísios que reduzem a quantidade de massas de ar úmidas provenientes do Atlântico e promovem o deslocamento da ZCIT, para 
fora de sua posição média (FISCH et al., 1998; FERNANSIDE, 2006; LIMA et al., 2013; NOBRE et al., 2013). Segundo Rojas e Alfaro (2000), o aquecimento (esfriamento) das TSM no Atlântico equatorial norte promove o deslocamento tardio (cedo) da ZCIT que pode retardar (avançar) o início da época de chuva na Venezuela.

No ano 2010, devido às fortes secas registradas na Venezuela, Tudares e Trejo (2013) avaliaram se as ocorrências dos eventos ENOS provocam ou não um efeito na diminuição das precipitações na Bacia do Rio Caroní. Concluíram que a bacia se encontra sob a influência dos eventos ENOS que são persistentes no tempo, tendo maior influência quando ocorre o fenômeno El Niño e La Niña do que quando ocorre a Oscilação do Sul.

Logo, o aquecimento anômalo das águas do Pacífico Equatorial apresenta maior influência nas precipitações do que a oscilação ao nível atmosférico. Esta conclusão também é apoiada pelos apontamentos de Obregon e Nobre (sf), os quais expõem que na região amazônica há maior correlação quando existem variações nas temperaturas dos oceanos Pacíficos e Atlânticos em termos de quantidade de precipitações do que os eventos de Oscilação do Sul.

Compreender o comportamento da frequência e severidade das queimadas, em relação aos impactos na vegetação frente às variações climáticas dos eventos ENOS e AMO que têm acontecido nos últimos anos, pode fornecer informação relevante para os gestores dessa importante área protegida, contribuindo para a preservação dos cursos de água que abastecem a Bacía do Rio Caroní e os ecossistemas, como também para o aproveitamento e otimização dos recursos naturais usados pelas comunidades indígenas necessários para sua subsistência. Uma vez que muitas práticas tradicionais indígenas de agricultura itinerante na região estão sendo consideradas ameaçadas, devido ao aumento da demanda dos recursos naturais associados às alterações demográficas e sócio-culturais das comunidades indígenas Pemón, como elevadas taxas de crescimento, mudanças nos padrões de assentamento e perda do conhecimento ancestral sobre o uso terra (FEARNSIDE, 2006; BILBAO et al., 2010).

Levando em conta esse panorama, as seguintes questões são colocadas: Como são distribuídas as frequências de focos de calor frente às variações ENOS e AMO no período de 2003 até 2014? A severidade das queimadas sobre a vegetação teve variação frente aos eventos ENOS e AMO? Quais são as áreas mais afetadas? Neste sentido, o objetivo do trabalho foi avaliar a frequência e severidade das queimadas ocorridas de 2003 a 2014 na GS - PNC - Venezuela frente às variações ENOS e AMO.

\section{MATERIAL E MÉTODOS}

\section{ÁREA DE ESTUDO}

Compreende um recorte da GS localizada dentro de dos limites PNC, englobando parte dos municípios Gran Sabana, Sifontes e Piar do Estado Bolívar, Venezuela (Figura 1). Abrange numa área de $7.656 \mathrm{~km} 2$ localizada entre as coordenadas geográficas $5^{\circ} 58^{\prime} \mathrm{N}$ a $61^{\circ} 62^{\prime} \mathrm{O}$ e $4^{\circ} 56^{\prime} \mathrm{N}$ e $61^{\circ} 9^{\prime} \mathrm{O}$.

Apresenta precipitações médias mensais superiores aos $60 \mathrm{~mm}$, e temperaturas do ar de 17 a $24^{\circ} \mathrm{C}$ as quais variam pela influência das variações 
na altitude, pela presença dos "Tepuys", denominação de origem indígena Pemón aos platôs elevados característicos desta região do Escudo das Guianas (HUBER et al. 2001; FLANTUA, 2008; DELGADO et al., 2009).

A distribuição e extensão espacial da vegetação é considerada heterogênea e variável pela presença de manchas de bosques com distintas altitudes e diferentes níveis de complexidade estrutural em associação com bosques secundários e vegetação arbustiva, tais como matorrales (matagal) e/ou helechos (samambaia dominados por Pteridium sp.) todos eles dentro de uma matriz de savana abertas. Sendo que estas variações nem sempre apresentam relação com as mudanças nas variações do relevo ou textura do solo (HERNÁNDEZ, 1994; DEZEEO et al., 2004; BILBAO et al., 2009).
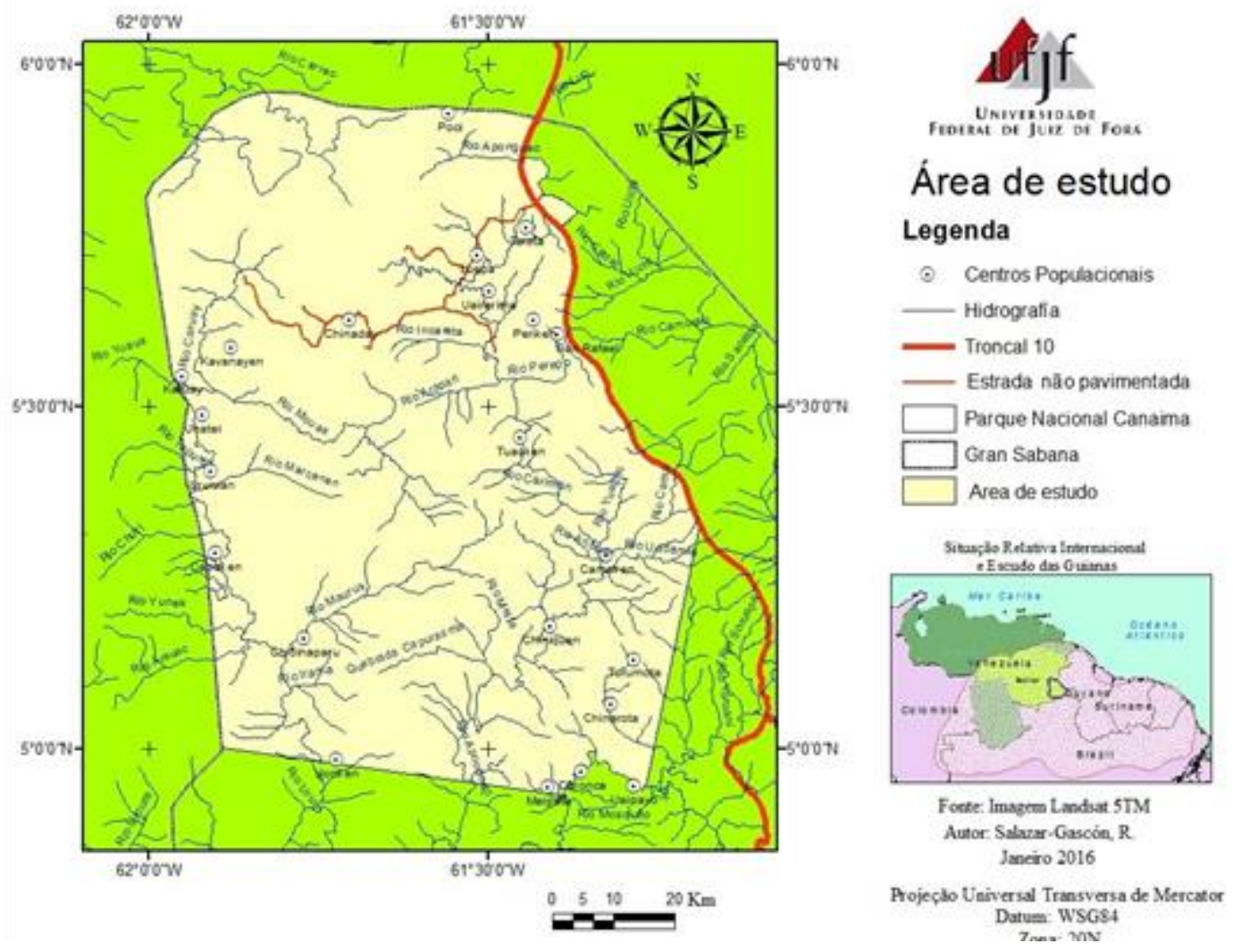

Figura 1 - Área de Estudo

\section{OBTENÇÃO E ANÁLISE DE DADOS}

As estações meteorológicas consideradas para o estudo estão na Tabela 1, com dados fornecidos pelo portal de Corpoelec no ano 2015. Para espacialização da precipitação, os dados foram interpolados pelo método de Krigagem linear. 
Tabela 1 - Estações Climáticas consideradas neste Estudo

\begin{tabular}{|c|c|c|c|c|c|c|}
\hline \multicolumn{3}{|c|}{ Localização (UTM/WSG84) } & \multirow{2}{*}{$\begin{array}{l}\text { Nome da } \\
\text { estação }\end{array}$} & \multirow{2}{*}{$\begin{array}{c}\text { Altitude } \\
\text { (m.s.n.m.) }\end{array}$} & \multicolumn{2}{|c|}{ Data de registro } \\
\hline $\mathbf{x}$ & $\mathbf{Y}$ & HUSO & & & Começo & Fina I \\
\hline 675259 & 659772 & $20 N$ & Sierra de lema & 1334 & $04 / 08 / 1988$ & $18 / 04 / 2015$ \\
\hline 659408 & 628460 & $20 N$ & Parupa & 1207 & $21 / 03 / 1974$ & $18 / 04 / 2015$ \\
\hline 638264 & 617384 & $20 N$ & Kavanayen & 1235 & 01/01/1959 & $18 / 04 / 2015$ \\
\hline 721124 & 567286 & $20 N$ & Compuiba & 902 & 01/01/1992 & $18 / 04 / 2015$ \\
\hline 704925 & 554949 & $20 N$ & Yuruani & 874 & $28 / 05 / 1974$ & $18 / 05 / 2015$ \\
\hline 640184 & 550864 & $20 N$ & Wonken & 817 & $01 / 01 / 1959$ & $18 / 04 / 2015$ \\
\hline 637796 & 543151 & $20 N$ & Caruaiken & 807 & $31 / 07 / 2001$ & $18 / 04 / 2015$ \\
\hline 573470 & 524819 & $20 N$ & Arapichi & 434 & $21 / 07 / 1977$ & $18 / 04 / 2015$ \\
\hline
\end{tabular}

Fonte: CORPOELEC.

Os índices das anomalias climáticas de ENOS (nas regiões do El Niño $1+2$ Niño 3, Niño 4, Niño3+4 ) e AMO (no Oceano Atlântico norte) foram obtidos pelo Clima Prediction Center do National Weather Service desde janeiro de 2002 até dezembro de 2014. Para apoiar a interpretação dos efeitos das anomalias climáticas na área de estudo, foram usados os resumos sinóticos obtidos no site: http://climanalise.cptec.inpe.br/ rclimanl/boletim/.

A frequência e distribuição dos focos de calor foram usados os produtos globais de sensoriamento remoto do satélite NOAA (National Oceanic Administration Atmosferic) series 12, 14, 15, 16, 17 e 18, contabilizados desde janeiro de 2003 até de dezembro de 2014 e fornecidos pelo Monitoramento de Queimadas e Incêndios do INPE. Para estimar a correlação linear entre as anomalias das TSM com precipitação e número de focos de queimadas, foi calculado o coeficiente de Pearson ( $r$ ), segundo Pacheco et al. (2012).

O índice genérico normalizado de ocorrência de queimadas (INQ), foi estimado de acordo com a metodologia de Carvalho Neto (2011), no qual é definido como a razão entre a frequência de focos de calor mensal $\left(F_{f i}\right)$, pela frequência máxima ( $\left.F_{f \max }\right)$ observada para o período de estudo, para um pixel $j$ (Fórmula (1))

$$
\mathrm{INQ}=\frac{\mathrm{F}_{\mathrm{fi}}}{\mathrm{F}_{\mathrm{fmax}}}
$$

As mudanças na cobertura de solo foram avaliadas com base na metodologia proposta por Xavier-da-Silva e Carvalho (1993) e na proposta de Menese-Tovar (2011), foi utilizado o Índice de Vegetação da Diferença Normalizada (NDVI), como indicador de degradação de florestas, no qual foi calculado no software Quantum Gis (QGis) 2.12.3 (Fórmula (2)). Onde NRI corresponde à banda do infravermelho próxima e VIS o espectro visívelvermelho. O uso do Índice de Vegetação da Diferença Normalizada (NDVI Normalized Difference Vegetation Index) desenvolvido por Rouse et al. (1973) foi escolhido por ser mais sensível à vegetação esparsa.

$$
\text { NDVI }=\frac{(\mathrm{NIR}-\mathrm{VIS})}{(\mathrm{NIR}+\mathrm{VIS})}
$$

A cobertura do solo foi determinada pela correção atmosférica, segmentação e posterior classificação não supervisionada das imagens da Tabela 2, correspondente aos períodos de secas, usando o software ENVI 5.0. Posteriormente, a mudança na cobertura do solo foi calculada com o software 
QGis 2.12.3. É importante ressaltar que a escolha das imagens foi determinada pela melhor resolução encontrada da área de estudo e com até $20 \%$ de cobertura de nuvens, as imagens foram retiradas no site da USGS: http://earthexplorer.usgs.gov/.

Tabela 2 - Imagens usadas para calcular NDVI e Cobertura do Solo

\begin{tabular}{cccc} 
Ano & Cena & Data & Landsat \\
\hline 2003 & 056_233 & $09 / 04 / 2003$ & 7 TM \\
2007 & $056 \_233$ & $11 / 03 / 2007$ & 5 TM \\
2009 & $056 \_233$ & $12 / 02 / 2009$ & 5 TM \\
2010 & $056 \_233$ & $30 / 01 / 2010$ & 5 TM \\
2014 & $056 \_234$ & $30 / 03 / 2014$ & 8
\end{tabular}

Tabela 3: Imagens usadas para determinar Cicatrizes de Queimadas

\begin{tabular}{cccc} 
Ano & Cena & Data & Landsat \\
\hline 2004 & 056_233 & $04 / 08 / 2004$ & 5TM \\
2014 & $056 \_234$ & $30 / 03 / 2014$ & 8
\end{tabular}

As cicatrizes de queimadas foram avaliadas nas imagens da Tabela 3, as quais foram escolhidas por possuírem uma cobertura de nuvens até $20 \%$, tendo sido retiradas no site USGS. A estimativa da cobertura das cicatrizes foi realizada segundo a metodologia proposta por Rashmi et al. (2014), com a ferramenta Semi-Automatic Classification com o Spectral Angle Mapping disponível no software QGis 2.12.3.

\section{RESULTADOS}

O clima no norte da América do Sul, além de ser influenciado pela orografia, os processos que acontecem no continente e as interações entre o continente e o mar, são também influenciados pelos oceanos através dos efeitos que provocam ao nível da atmosfera (MARTELO, 2003, NURMOHAMED et al., 2006; POVEDA et al., 2006). Assim, anomalias nas TSM dos Oceanos Pacífico e Atlântico equatorial afetam os regimes de precipitação na Amazônia (DEBORTOLLI, 2014; GRIMM et al., S/F; NOBRE et al., 2013; POVEDA et al., 2006; MENDOÇA et al., 2007). 


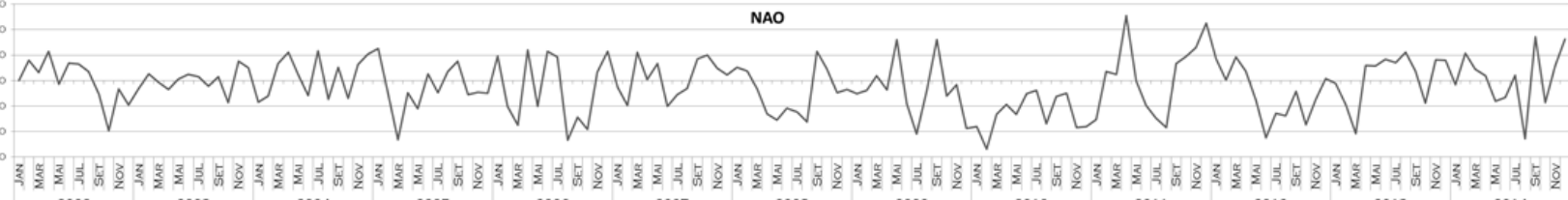

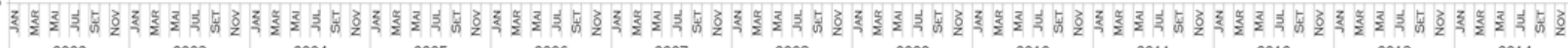

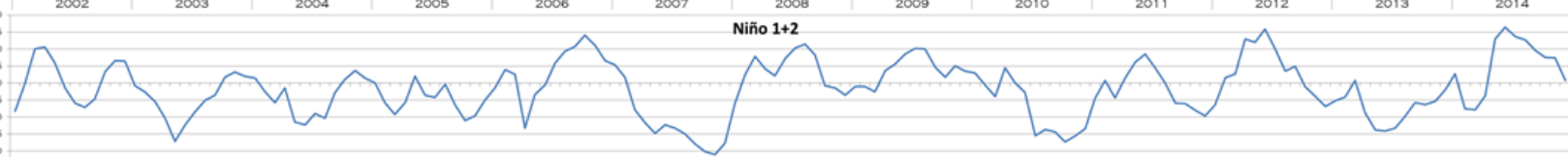

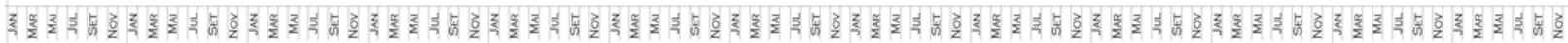

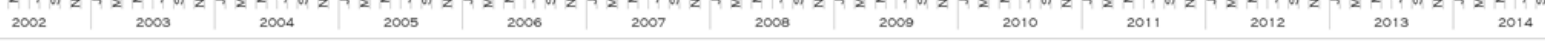

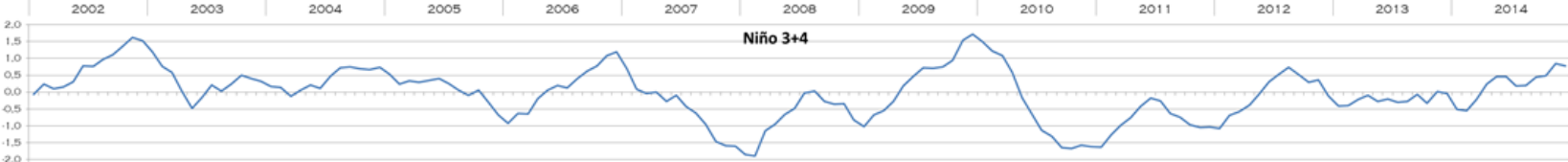

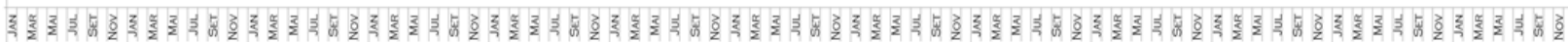

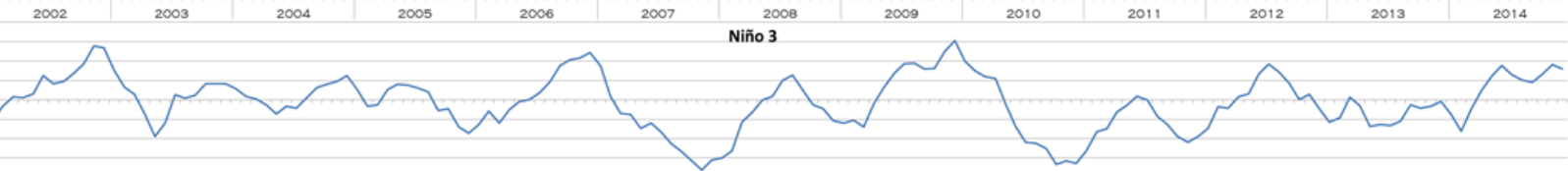

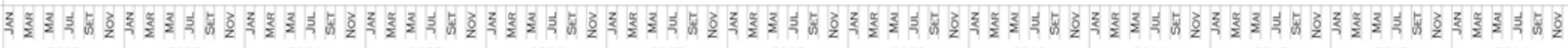
\begin{tabular}{|l|l|l|l|l|l|l|l|l|l|l|l|l|l|}
2002 & 2003 & 2004 & 2005 & 2006 & 2007 & 2008 & 2009 & 2010 & 2011 & 2012 & 2013 & 2014 \\
\hline & & & & &
\end{tabular}

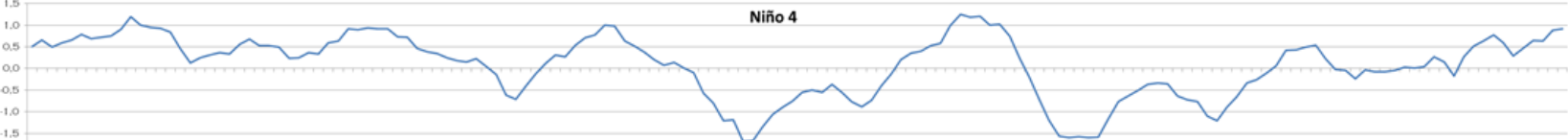

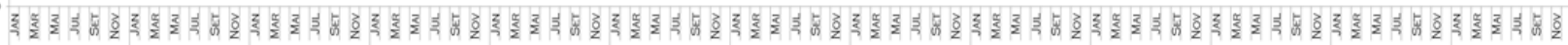
\begin{tabular}{|l|l|l|l|l|l|l|l|l|l|l|l|l|l|l|l|l}
2002 & 2003 & 2004 & 2005 & 2006 & 2007 & 2008 & 2009 & 2010 & 2011 & 2012 & 2013 & 2014
\end{tabular}

Figura 2 - Anomalias na TSM (Temperatura na Superfície do Mar) para estimação do ENOS (região El Niño 1+2, Niño 3+4, Niño 3 e Niño 4) e AMO (Região do Oceano Atlântico Norte -NAO pelas siglas em inglês) desde 2002 até 2014.

Na Figura 2 são apresentadas as anomalias das TSM, evidenciando-se o topo mais elevado do AMO no ano 2011 e 2012, com amplitude maior entre metade de 2007 e início de 2010, apresentando amplitudes menos fortes a partir do ano 2011 e com maior variabilidade. A região do El Niño 1+2, apresentou maior variabilidade com elevada frequência de aquecimento positivo de 2002 a 2006, com quedas significativas no ano 2007 e nos meses finais de 2010. No entanto, as regiões do El Niño 3, Niño 4 e Niño 3+4 apresentaram fases de aquecimento com menor variabilidade e maior amplitude ao longo da série temporal, destacando-se desde finais de 2002 até o início de 2008 com anomalias positivas na TSM com fases de resfriamento menos intensas. No ano de 2011, houve um aumento nas anomalias de forma gradual até dezembro de 2014.

A Figura 3 apresenta a distribuição espacial das chuvas, ressalta-se que a quantidade de meses com secas mais intensas, de 2 até 3 meses contínuos, ocorreram nos anos de 2003 e 2007. Apresentando no mês de janeiro de 2006, uma condição anômala, com valores mais elevados de precipitação aos esperados nesse período. No ano de 2008 houve um ligeiro déficit na quantidade de precipitações no período chuvoso e um pequeno aumento nas precipitações durante os períodos de secas. No entanto, para o ano 2009, o período tradicionalmente de seca, apresentou precipitações um pouco acima do 
esperado, estendendo-se até o mês de maio, o déficit de precipitação foi menos intenso e mais constante ao longo do período de chuvas, apresentando outro intenso déficit no mês de dezembro, estendendo-se até o mês de março do ano 2010. A partir de abril do ano de 2010 ocorreram chuvas acima da média, com aumento significativo no mês de agosto, que estendeu-se em menor grau até dezembro. Entre janeiro de 2011 e dezembro de 2012 se estabeleceram padrões de precipitações com características similares as apresentadas no ano 2008. Esse mesmo padrão se evidência no ano 2014 e com menor grau no ano 2013 com os meses de janeiro e março apresentando intensas secas.

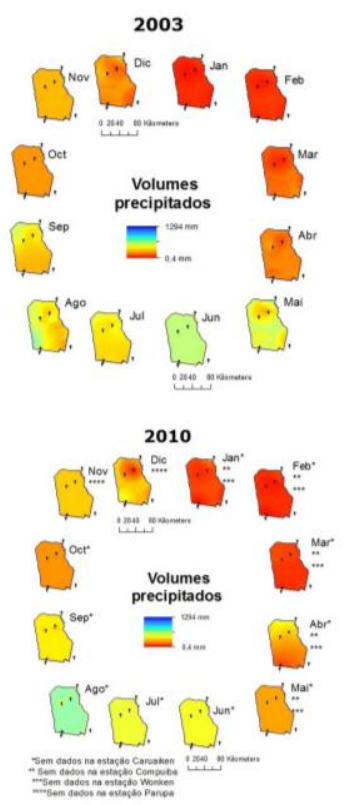

2011

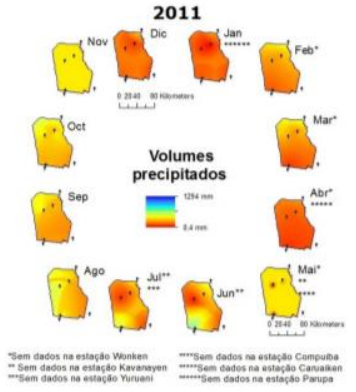

Projeção Universal Transversa de Mercator Datum WSG84 - Zona $20 \mathrm{~N}$
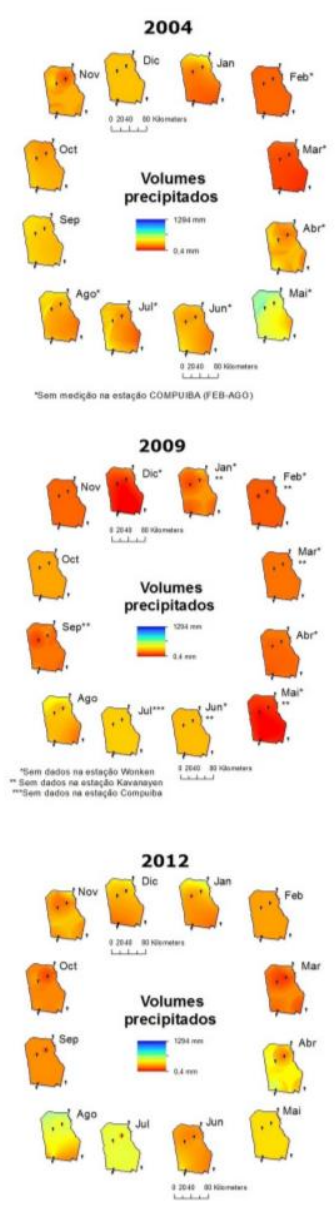

Fonte: Corpoelec
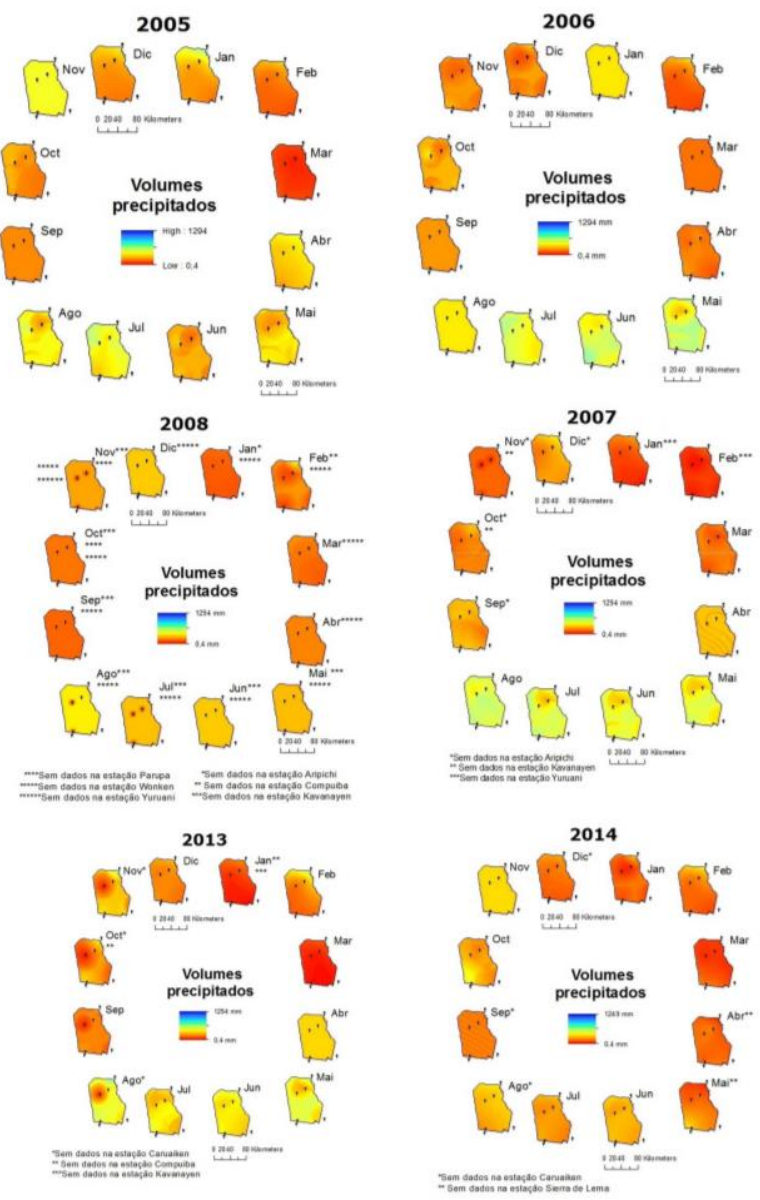

Autor: Salazar-Gascón, R.

Setembro 2015

Figura 3 - Pluviosidade mensal de 2003 a 2014 na área de estudo

Na Figura 4, destaca-se que existe uma correlação fraca negativa em todas as estações na região do El niño $1+2$ no Pacífico, apresentando uma anomalia positiva (aquecimento) desta zona provocando uma diminuição na quantidade de pluviosidade na área de estudo. Assim, um aquecimento na região do El Niño 4, apresenta uma correlação fraca positiva, o que se traduz num incremento das TSM, acarretando em um aumento da pluviosidade nessa área. As áreas de menor altitude, que se encontram nas zonas de vales, 
apresentam uma correlação ínfima negativa com a oscilação das temperaturas no Atlântico norte. Já, as regiões de maior altitude, apresentam uma relação ínfima positiva com estas anomalias (Figura 4 e Tabela 1).

Porém, pode-se verificar que a Célula de Walker provavelmente apresenta um deslocamento longitudinal segundo a fase de maior influência do El Niño, o que promove diferentes expressões na quantidade de precipitação nesta região. Quando são apresentados os aquecimentos nas TSM do Pacífico na região do El Niño $1+2$ em sincronia com aquecimentos no AMO, se vê favorecida a influência do Atlântico - e, segundo Rojas e Alfaro (2000), este se potencializa nas épocas de chuvas na Venezuela - como aconteceu no ano 2006 (Figura 4).

Logo, as anomalias do Pacífico nas regiões do El Niño 1+2, El Niño 4 apresentam correlações fracas, com intensidade similar, mas com sentidos diferentes sobre a região em termos da capacidade de modelar as precipitações. Nobre et al. (2013) apontam que a Amazônia se encontra influenciada pela presença de um dipólo nas temperaturas do Atlântico tropical, e segundo Nurmohamed et al. (2006), Martelo (2004), Nobre et al. (2013) e Debortolli (2014), principalmente pelo aquecimento nas TSM do Atlântico Tropical Norte. No caso do Oceano Pacífico equatorial, os autores afirmam que uma influência do aquecimento das TSM promove a extensão dos períodos de secas na região Amazônica (GRIMM et al., S/F; CÁRDENAS et al., 2002; FISCH et al., 1998; MARTELO, 2004, NURMOHAMED et al., 2006; POVEDA et al., 2006; PAOLINI et al., 2012; NOBRE et al., 2013; DEBORTOLLI, 2014).

Cohefficente de Pearson (r) estimado para cada estação Gran Sabana-Parque Nacional Canaima-Venezuela
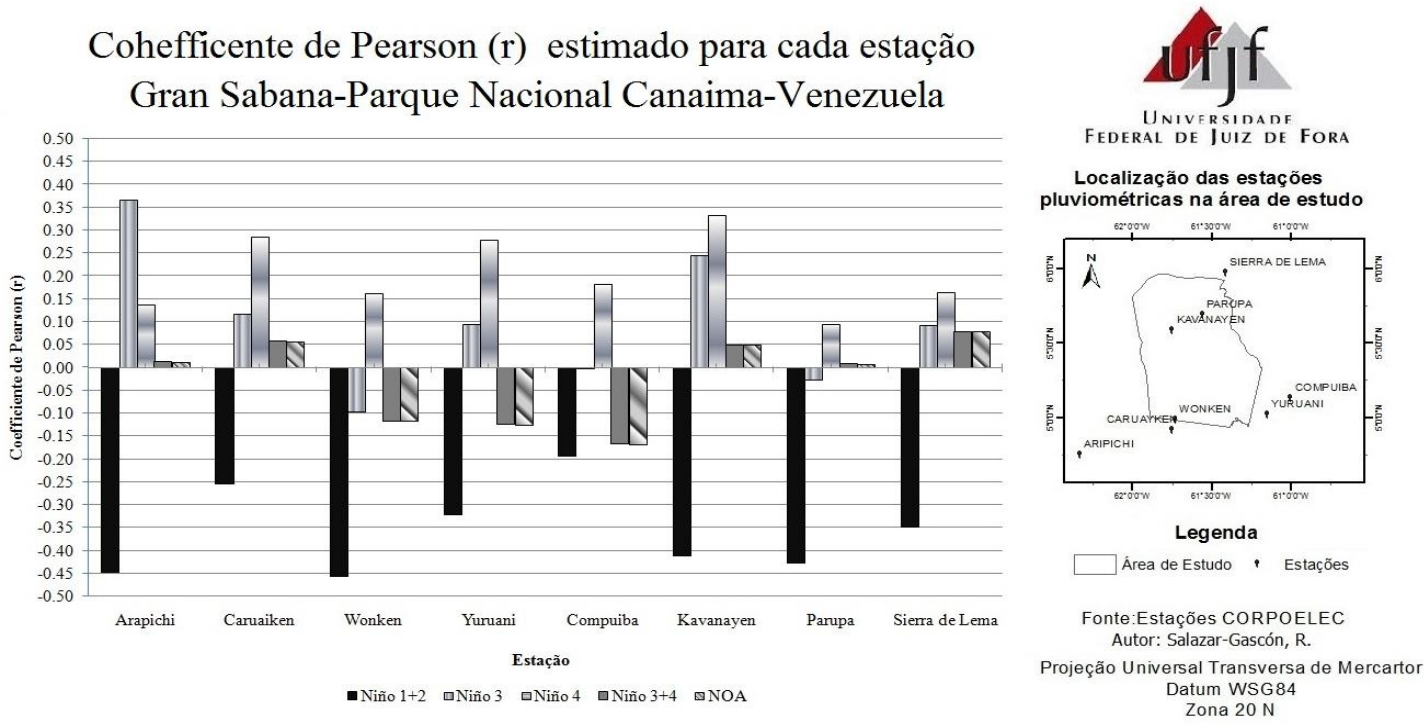

Figura 4 - Coeficiente de Pearson ( $r$ ) em cada estação utilizada para avaliar a influência das anomalias ENOS (região do El Niño 1+2, Niño 3, Niño 4, Niño 3+4) e AMO (NOA) na área de estudo

Poveda et al. (2006) apontam que a variabilidade das precipitações ao norte do América do Sul e na Venezuela, particularmente, é muito complexa pela geografia da região. Segundo Nobre et al. (2013), a principal fonte de umidade na Região Amazônica se encontra no Oceano Atlântico, apresentando um fluxo persistente para o norte na maior parte do ano. Sendo que na 
Venezuela os períodos de chuvas e secas se encontram modulados principalmente pelo posicionamento da ZCIT (ROJAS E ALFARO, 2000).

A frequência de focos de calor detectados pelos satélites foi diminuindo ao longo da série temporal estudada, apresentou os máximos valores no ano 2003, 2004 e 2006, com valores mínimos no ano 2012, com quedas na tendência do ano 2005 e outra mais significativa a partir de 2008, que se manteve mais ou menos estável até 2014 (Figura 6-a). A variabilidade dos focos de calor representado na figura 6 ressalta que no período de chuvas (Figura 6 b) do ano 2006 apresentou o valor mais elevado com alta variabilidade na quantidade de focos de calor pelo elevado número de incêndios reportados para o mês de abril. Porém, o período de seca (Figura 6-c) apresentou um maior número de incêndios com alta variação em 2003 e 2007, a elevada variabilidade se deve ao pequeno número de incêndios registrados no mês de janeiro, destacando nesse mesmo mês do ano 2005 com nenhum foco de calor detectado.

Na tabela 4 estão apresentados os coeficientes de correlação de Pearson entre as anomalias climáticas e a quantidade de incêndios. Obteve-se uma correlação fraca positiva em relação aos fenômenos do El Niño 4, ínfima positiva em relação ao El Niño 3 e El Niño 3+4, é dizer ao incremento (diminuição) destas anomalias maior (menor) número de focos de calor podem acontecer na área de estudo. No entanto, para o fenômeno AMO e El Niño $1+2$ obteve-se uma correlação ínfima negativa que implica maior (menor) anomalia nas TSM do Atlântico Norte, o que reflete em uma diminuição (aumento) na quantidade de focos de calor detectados pelos satélites.

Tabela 4 - Coeficiente de Pearson (r) entre a frequência de focos de queimadas e anomalias

\begin{tabular}{ccc} 
Anomalía & $\mathbf{r}$ & Relação \\
\hline Niño $1+2$ & -0.06 & Ínfima negativa \\
Niño 3 & 0.07 & Ínfima positiva \\
Niño 4 & 0.12 & Fraca positiva \\
Niño 3+4 & 0.04 & Ínfima positiva \\
NOA & -0.08 & Ínfima negativa
\end{tabular}

Enquanto ao INQ apresentado na Figura 6-d, no período que abrangede 2003 a início de 2008, observou-se uma contribuição maior de focos de calor dentro da série temporal de estudo, ressaltando que os primeiros trimestres dos anos 2003, 2004, 2005 e 2007 apontaram um maior INQ em proporção a média da série temporal considerada. Porém, o ano 2006 apesar de ter valores elevados nos primeiros 5 meses do ano, apresentou uma pequena queda na metade do período.

Os resultados alcançados corresponderam com os produtos obtidos para a mesma região da pesquisa de Chen et al. (2011), na qual foi apresentado um modelo preditivo de incêndios na América do Sul, que foram comparados com os resultados MODIS, de acordo com as inter-relações das anomalias das TSM no 
Atlântico e Pacífico equatorial no ano 2001 até 2010. Destacando que os anos 2004, 2005 e 2007 apresentaram elevados valores de AMO e ONI (índice de oscilação do El Niño) e grande quantidade de incêndios durante os períodos de janeiro até março. Assim no ano 2009, tanto AMO quanto ONI tiveram valores negativos que diminuíram a quantidade de incêndios.

O padrão foi também observado nos resultados obtidos no presente trabalho, figura 5 especialmente no INQ. Porém, as diferenças no comportamento da quantidade de incêndios ocorridos no ano de 2010 , onde se verificou uma queda na quantidade de incêndios, tanto no período de seca quanto das chuvas, na região de estudo (Figura $6 \mathrm{~b}$ e $6 c$ ). Este fato, deve-se a uma grande quantidade de focos de calor na região centro sul da América do Sul, já que na região norte encontrou-se influenciada pelas chuvas, produto da localização anômala da ZCIT apontado anteriormente, que são mostradas nas correlações apresentadas da tabela 4. 

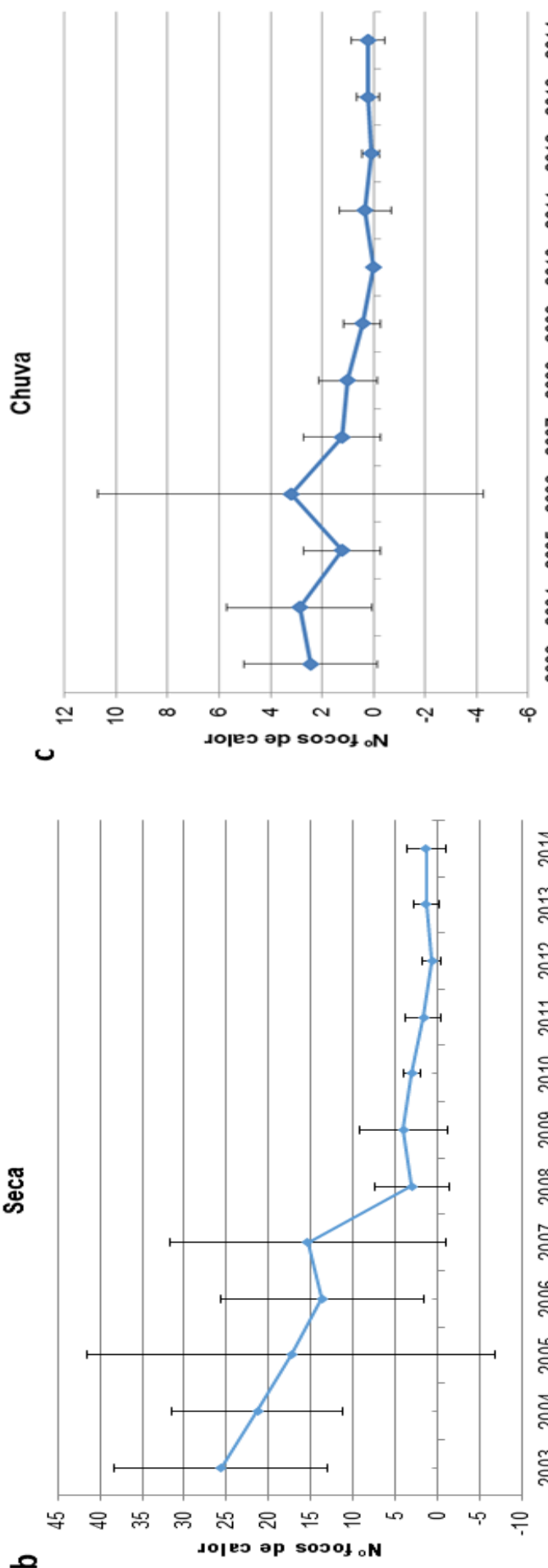
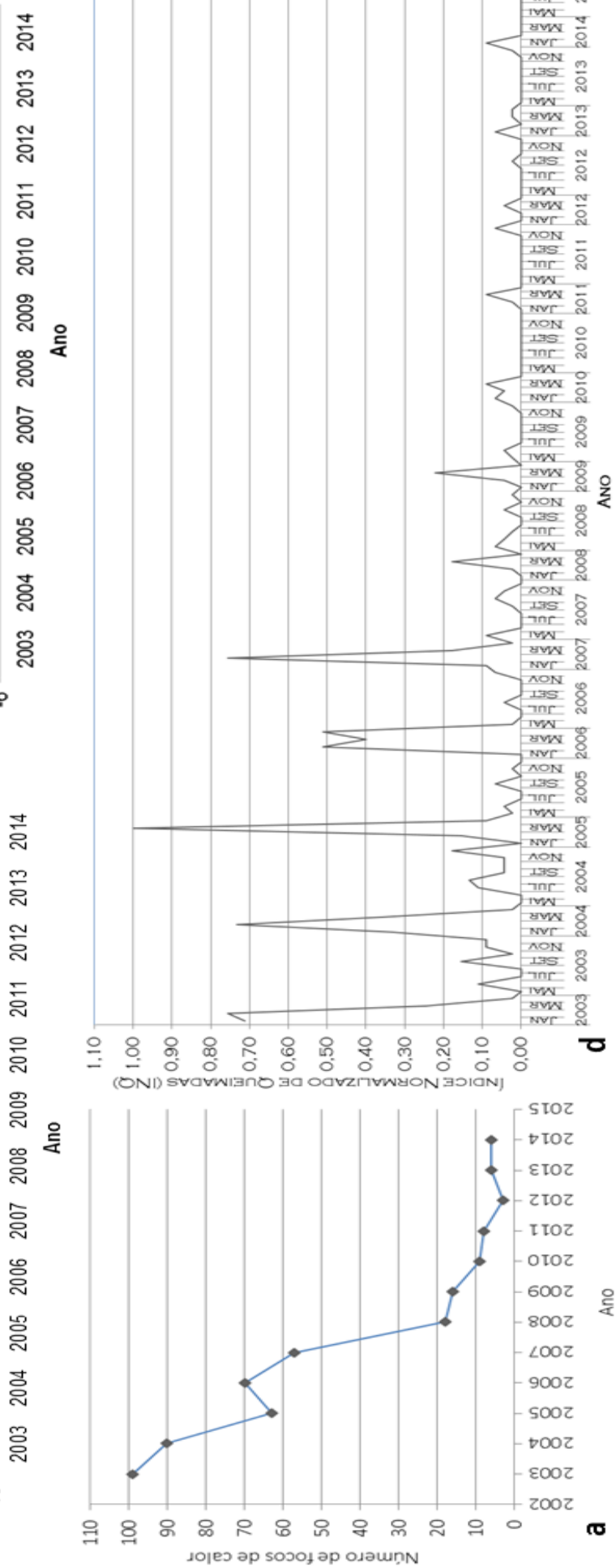

Figura 5 - Número de focos de calor (a) em períodos de chuvas (b), períodos de secas (c) e Índice Normalizado de Queimadas (INQ) de ano 2003 a 2014(d). Fonte: Elaborado pela autora a partir dos dados do Satélite NOAA series 12, 14, 15, 16, 17 e 18. 
A distribuição de focos de calor (Figura 6) coincide com a cercania aos centros populacionais e as regiões identificadas como zonas de vida "herbáceas" e "mistas arbustivas". Evidenciando-se que a maioria das queimadas ocorreram na porção leste da área de estudo, e que nos anos 2003, 2004, 2005, 2006 e 2007 a distribuição, mesmo concentrada na porção leste, teve uma abrangência maior dentro da área de estudo. Desta forma, na figura 9 são apresentadas a distribuição das cicatrizes de queimadas no período de 2004 a 2014, evidenciando-se que muitas áreas queimadas se encontram próximas aos cursos de água, e aos assentamentos principais.

Notou-se, especialmente no ano de 2014, no qual são verificados uma menor quantidade de polígonos (tabela 5), porém estas possuem uma maior abrangência territorial, como o polígono que está demarcado no centro da área de estudo, este fato pode esta relacionado com áreas usadas recentemente para mineração por parte das comunidades locais.
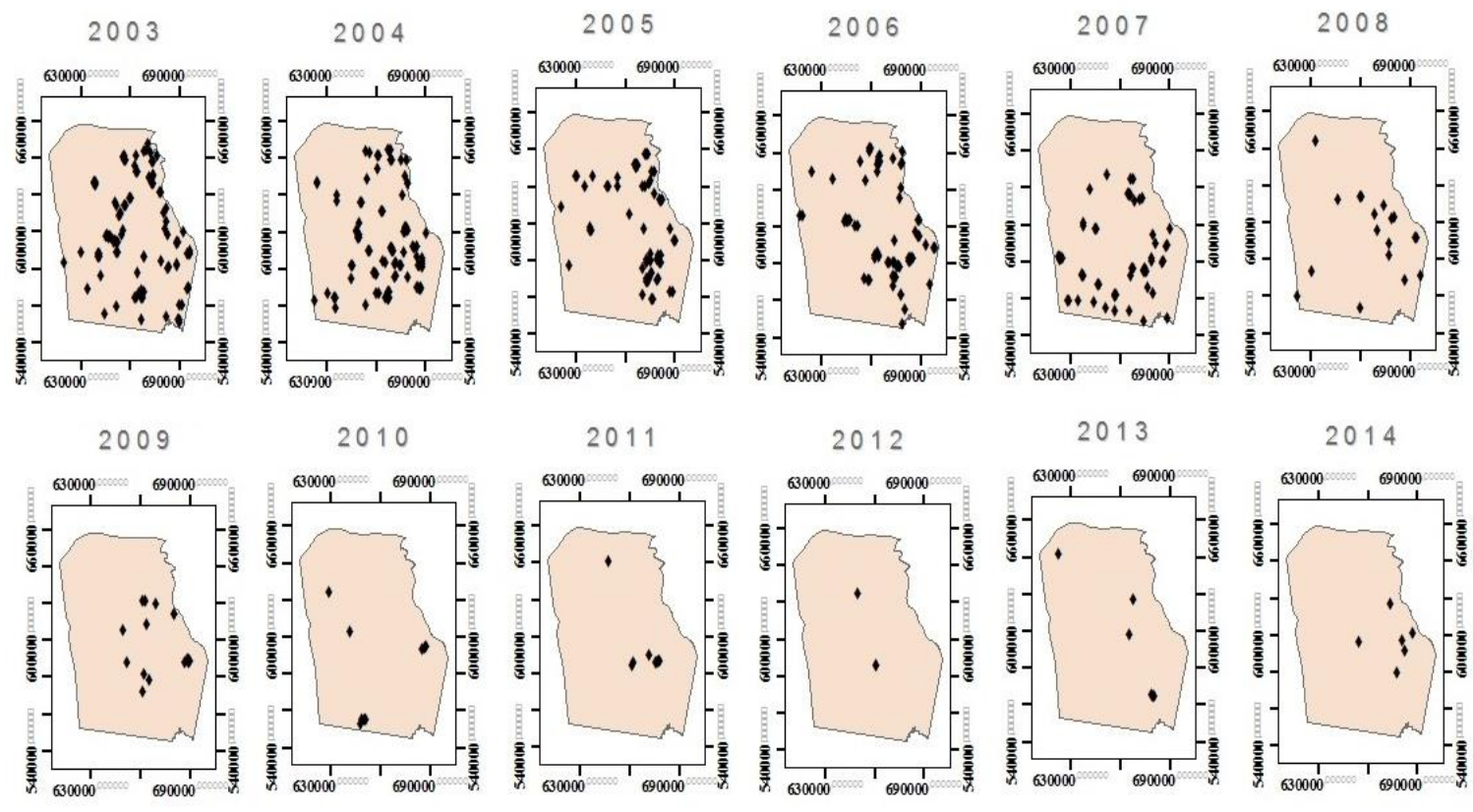

Legenda

- Focos de queimadas Area_Estudo
Projeção Universal Tranversa de Mercator Datum WSG 84 - Zona $20 \mathrm{~N}$
Fonte: Satélite sensor NOAA Autor: Salazar-Gascón, R. Julho 2015

Figura 6 - Distribuição dos focos de calor na área de estudo de ano 2003 a 2014.

Rodriguez (2004) e Rodriguez e Sletto (2009) apontam o homem como o principal responsável pelos incêndios. Em consequência, a distribuição dos focos de calor (Figura 6) estão associados às atividades humanas, com isso estão localizados nas proximidades dos principais centros populacionais assentados na região (Figura 1). Assim, as mudanças nas práticas culturais do uso do fogo reportadas por Rodriguez et al. (2004) e Bilbao et al. (2010), podem refletir em mudanças nos padrões das cicatrizes de queimadas (Figura 7). 
Tabela 5 - No cicatriz de queimadas e área que abrange em 2004 e 2014

\begin{tabular}{ccc} 
Ano & No Polígonos & Área total $\left.\mathbf{( K m}^{\mathbf{2}}\right)$ \\
\hline 2014 & 1640 & 26.05 \\
2004 & 4492 & 78.27
\end{tabular}

Fonte: Elaborada pela autora com Imagens Landsat 5TM (2004) e Landsat 8 (2014)

Passando de um uso do fogo primordialmente agrícola, que são identificados por uma distribuição ao longo dos cursos dos rios como ocorre em 2004. Flantua (2008) aponta que o estabelecimento dos "conucos" ou parcelas agrícolas para semear produtos de rápido crescimento, é indispensável, segundo os requerimentos das populações locais, à proximidade de algum curso de agua. Mais recentemente o uso do fogo, também está atrelado as atividades mineradoras. Percepção esta que pode ser apoiada no trabalho de Flantua (2008), que identificou e calculou os padrões de distribuição de mineração dentro e fora do PNC, que equivalem em sua maior parte às cicatrizes de queimadas mapeadas neste estudo (Figura 7).

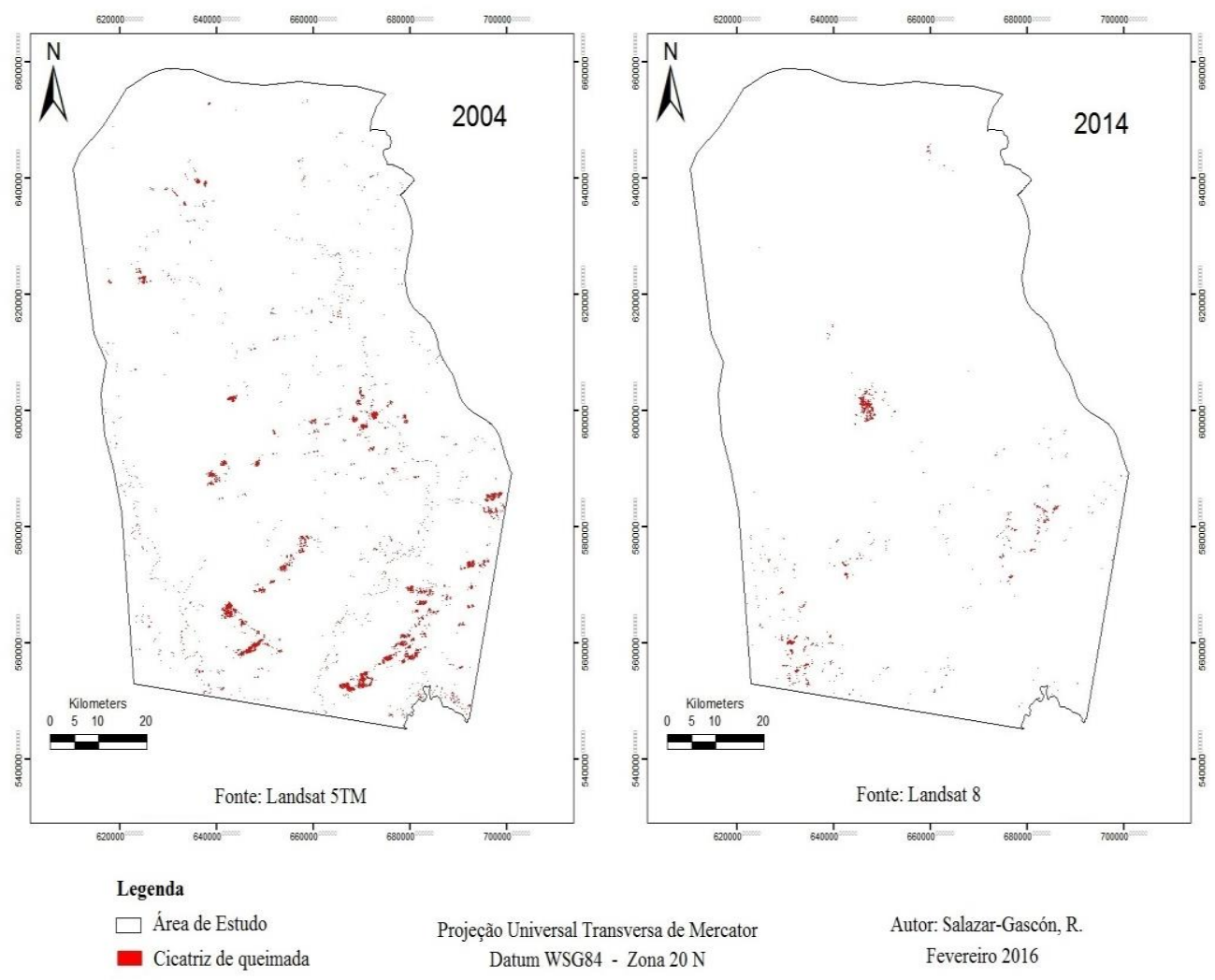

Figura 7 - Cicatriz de queimadas detectadas para área de estudo em 2004 e 2014

Finalmente, Carcaillet et al. (2001) propõe que a vegetação não controla os regimes de fogo no longo prazo, apontando ao clima como principal fator determinante na ativação de produção do fogo diante o aumento na frequência de secas. Leal (2010) aponta que existem padrões ao nível local que modulam 
esses regimes e que são independentes dos fatores antrópicos e macroclimáticos regionais.

\section{CONCLUSÕES}

A severidade e frequências das queimadas na GS são um processo multifatorial e multiescalar que acontecem como produto da sincronia dos fatores ecossistêmicos (vegetação), sociais (proximidade aos centros populacionais) e climáticos (ENOS e AMO). As anomalias das TSM no Atlântico Equatorial Norte (AMO) quando acontecem em sua fase quente afetam a localização da ZCIT, alterando o padrão de circulação da célula de Hadley e promovem a ocorrência dos processos convectivos na GS, incrementando as precipitações. As anomalias das TSM no Pacífico Equatorial (ENSO) em sua fase positiva El Niño (fases $1+2,3,43+4$ ) provocam alterações nos padrões de circulação da Célula de Walker, inibindo os processos de subsidência, o que promove um déficit na pluviosidade, refletindo na extensão dos períodos de secas.

As anomalias das TSM no Pacífico Equatorial (ENSO) em sua fase negativa, La Niña, promove a ocorrência de processos de subsidência gerando um incremento na pluviosidade. Quando acontecem simultaneamente anomalias positivas no AMO e anomalias negativas no ENOS, processos convectivos se potencializam gerando grandes volumes de precipitação. Quando acontecem simultaneamente anomalias positivas no AMO e ENOS, se vê favorecida o AMO, gerando um deslocamento anômalo da ZCIT, afetando o começo das estações de seca ou chuvas.

As secas prolongadas, produto das anomalias climáticas El Niño, contribuem na degradação dos sistemas arbóreos, na expansão dos sistemas herbáceos e no incremento da frequência de queimadas. A distribuição das cicatrizes de queimadas se encontram fortemente associadas às mudanças nos padrões culturais de subsistência das populacionais locais, em maior medida que as anomalias climáticas.

Intensas chuvas produto das anomalias climáticas AMO, La Niña, ou ambas, contribuem na expansão dos sistemas arbustivos, e em menor grau na recuperação dos sistemas arbóreos mistos e arbóreos.

\section{AGRADECIMENTOS}

Ao Programa da Organização dos Estados Americanos (OEA) e Grupo Coimbra de Universidades Brasileiras (GCUB) e CAPES por fornecer bolsa de estudo durante estes dois anos, e ao Programa de Pós-graduação da Geografia da UFJF por fornecer alguns dos recursos para assistência em eventos acadêmicos para apresentação do trabalho.

\section{REFERENCIAS BIBLIOGRÁFICAS}

ABLAN, M., DÁVILA, M., HOEGER, H.; RAMOS, A., RIVAS, E.; ZERPA, F. Modelling Fire Risk: The Upper Caroni Watershed Case. Proceedings of the VI 
ASTED International Conference on Modelling, Simulation and Optimization. 6p. 2005.

BARUCH, Z. Vegetation-environment relationships and classification of the seasonal savannas in Venezuela. Flora (200). 49-64pp. 2005.

BILBAO, B.; LEAL, A. e MENDEZ, C. Indigenous use of fire and forest loss in Canaima National Park, Venezuela. Assessment and tools for alternative strategies of fires management in Pemon indigenous land. Human Ecology. 80p. 2010.

BILBAO, B.; LEAL, A.; MENDEZ, C.; DELGADO-CARTAY, M.D. 16: The role of fire in the vegetation dynamics of upland savannas of the Venezuelan Guayana. In: COCHRANE, M.(org.). Tropical Fire: Climate change, land use, and ecosystem dynamics. Chichester: Praxis Publishinhing. 451-480 pp. 2009

BRICEÑO, H. O. e SCHUBERT, C. Geomorphology of the Gran Sabana, Guayana Shield, southeastern Venezuela. Geomorphology Vol. 3: 125-141pp. 1990.

CARCAILLET, C.; BERGERON, Y.; RICHARD, P.; FRÉCHETTE, B.; GAUTHIER, S. Y PRAIRIE, Y. Change of fire frequency in the eastern Canadian boreal forest during the Holocene: does vegetation composition or climate trigger the fire regime?. Journal of Ecology. Vol. 89: 930-941 pp. 2001.

CARDENAS, P; GARCÍA, L.F E GIL, A. Impactos de los eventos El NiñoOscilación del sur em Venezuela. Caracas: Coorporación Andina de Fomento (CAF), 131pp. 2002.

CHEN, Y.; RANDERSON, J. T.; MORTON, D. C.; DE FRIES, R.S.; COLLATZ, G. J.; KASIBHATLA, P. S.; GIGLIO, L.; JIN, Y. e MARLIER, M. E. Forecasting fire season severity in South America using sea surface temperature anomalies. Science. Vol.: 334. 2011.

CHRISTOFFEL, H.M. Informe definitivo sobre los suelos y possibilidades agrícolas en la Gran Sabana. In Aguerrevere, S.E.; Lopez, V.; Delgado C. e Freeman C. (eds.). Exploracion e la Gran Sabana. Revista de Fomento 3: 596631 pp. 1939.

DE CARVALHO NETO, G.; NOGUEIRA, J.M.P; COELHO, G. L. N; MORENO, L.P. e DELFINO BARBOSA, J.P.R.A. Aplicação de produtos globais de sensoriamento remoto para estudo do regime de queimadas em diferentes escalas espaciais na América do Sul. Anais XV Simpósio Brasileiro de Sensoriamento Remoto. Curitiba. 3142-3149 p. 2011.

DEBORTOLI, N. A Amazônia sujeta a secas. Dry Amazonia. Brasilia: Sustentabilidade em debate. Vol. 5. No:1: 174-178 pp. 2014.

DELGADO, L.; CASTELLANOS, H. Y RODRIGUEZ, M. Capítulo 2: Vegetación del Parque Nacional Canaima. In: SEÑARIS, J.C.; LEW, D. E LASSO, C. (Editores) Biodiversidad del Parque Nacional Canaima. Bases técnicas para la conservación de la Guayana Venezolana. Caracas: Fundación La Salle de Ciencias Naturales y The Nature conservancy. 39- 73pp 2009.

DEZZEO, N; FÖLSTER, H. e HERNÁNDEZ, L. El fuego en la Gran Sabana. Interciencia. Vol 29. 2004.

EDELCA. La cuenca del Río Caroní. Una visión en cifras. CORPOELECElectrificación del Caroní (EDELCA) 263 p. 2008. 
EDEN, M. Paleoclimatic influences and the development of savanna in southern Venezuela. Journal of Biogeography, Vol.1: 95-109pp. 1974.

ELCORO, S. e VERA, N. Estudio de rastrojos en áreas con altas concentraciones de población en Kavanayén, la Gran Sabana Estado Bolívar. 68 pp Monografia. (Bacherolado em Ciencias forestales). Universidad de los Andes, Mérida, Venezuela.. 1986.

FEARNSIDE, P. Desmatamento na Amazônia: dinámica, impactos e controle. Acta Amazonica. Vol. Na36. 395-400 pp. 2006.

FISCH, G.; MARENGO, J.; NOBRE, C.A. Uma revisão geral sobre o clima da Amazônia. Acta Amazonica. Vol. Na28. 101-126 pp. 1998.

FLANTUA, S. G. A. Land use and Land-cover changes in the Sector II. Kamarata The National Park Canaima, Venezuela. Master Project Biological Sciences. University of Amsterdam, Netherlands. Universidad Simón Bolívar, Venezuela. Univesity of Leicester, United Lingdom. 2008.

FÖLSTER, H. Y DEZZEO, N. La degradación de la vegetación. In: DEZZEO, N (ed.). Ecología de la altiplanicie de la Gran Sabana (Guayana Venezolana) I. Scientia Guaianae, No 4: 145-186 pp. 1994.

GÓMEZ, E., PICÓN, G.; BILBAO, B. Los incendios forestales en Iberoamérica. Caso Venezuela. In.: Vélez-Muñoz, R. (ed.). La defensa contra incêndios forestales. Fundamentos y experiências. Madrid: McGraw-Hill. (2000).

GRIMM, A.M.; ZARATINI, P. e MARENGO, J. Sinais de El Niño na precipitação da Amazôna. Anais do X Congresso Brasileiro de Meteorologia. Sociedade Brasileira de Meteorologia.6p.s/f.

HERNÁNDEZ, L. e FÖLSTER, H. Vegetación en transición. In: Dezzeo N. (ed.). Ecología de la altiplanicie de la Gran Sabana (Guayana Venezolana) I. Scientia Guaianae, N 4. 118-144. 1994.

HUBER, O. La vegetación de la cuenca del Río Caroní. Interciencia. Volº11: 301 310pp. 1986.

HUBER, O. Shrublands of the Venezuelan Guayana. In: HOLME-NIELSEN, L. B.; NIELSEN, I. C. E BASLEV, H. (eds.)Tropical Forest. Londres,:Academic Press. 271-285 pp. 1989.

HUBER, O. 3.Vegetation. In: STEYERMARK, J.A. BERRY, P.E. e HOLST, B.K. (Eds.). Flora of the Venezuelan Guayana. Missouri: Botanical Garden Timber Press. 97-159 pp.1995.

HUBER, O.; FEBRES, G. E ARNAL, H. Ecological guide to Gran Sabana. The Nature Conservancy. Caracas. 189 pp. 2001.

LIMA, A.; ARAGÃO, L.E.O.; BARLOW, J.; SHIMABUKURO, Y. Y.; ANDERSON, L. O. E DUARTE, V. Treze: Severidade dos incêndios florestais em anos de seca extrema. In: BORMA, L. D.S e NOBRE, C. A.(org.). Secas na Amazônia: Causas e consequências. São Paulo: Oficina de Textos, 180-205 p. 2013.

LEAL, A. V. Historia holocena de la vegetación y el fuego em bordes sabana/bosque y turberas de la Gran Sabana, Guayana Venezolana. 236p. Tesse (Doctorado en Ciencias Biológicas)- Decanato de estúdios de postgrado, Universidad Simón Bolívar, Sartenejas, 2010. 
MARTELO, M. T. Influencia de las variables macroclimáticas en el clima de Venezuela. Caracas: Dirección de Hidrología, Meteorología y oceanologia. Ministerio del Ambiente y los Recursos Naturales (MARN). 72 pp. 2003.

MENDOÇA, F. E DANNI-OLIVEIRA, I. M. Climatología noções básicas e climas do Brasil. São Paulo: Oficina de Textos. 206 pp. 2007.

MENESES-TOVAR, C. El índice normalizado diferencial de la vegetación como indicador de la degradación del bosque. Unasylva 238. Vol.:62.2011.

NOBRE, C. A.; OBREGón, G.O. E MARENGO, J. A. Características do Clima Amazônico: Aspectos principais. In: KELLER, M.; BUSTAMANTE, m.; GASH, J. E DIAS, P.S. (editores). Amazonia and Global Change. Geophysical Monograph Series. Vol. No 186. 149-162 p. 2013.

NURMOHAMED, R.; NAIPAL, S. E BECKER, C.Rainfall variability in Suriname and its relationship with the Tropical Pacific ENSO SST anomalies and the Atlantic SST anomalies. ACTA NOVA; Vol. 3, No 3: 15p. 2006.

PACHECO, B.L.S; SILVA JÚNIOR, L.G.; OLIVEIRA, L.A. Estudo da relação entre temperatura/altitude e precipitação/altitude aplicando-se os Métodos de correlação e regressão. Revista Geonorte. Edición especial 2, N05. 561-572p. 2012.

PAOLINI, J.; FELIPE, J.J.; SUREDA, B. e ROSALES, J. Influencia Del fenómeno El Niño-La Niña/Oscilación Sur (ENOS) y de La temperatura Del Atrlántico norte em los caudales Del Río Caura, Guayana Venezolana. Revista de climatologia. Volo:12:23-32pp. 2012

POVEDA, G.; WAYLEN, P. R.; PULWARTY, R. S. Annual and inter-annual variability of the presente climate in northern South America and Southern Mesoamerica. Palaeo. Vol. 234. 3-27 pp. 2006.

RAMIREZ, N.; DEZZEO, N. E CHACÓN, N. Floristic composition, plant aundance, and soil properties of montane savanas in the Gran Sabana, Venezuela. Flora. Vol.: 202. 316-327pp. 2007.

RASHMI, S; ADDAMANI, S. E RAVIKIRAN, S. Spectral angle mapper algorithm for remote sensing image classification. International Journal of Innovative Science, Engineering \& Tecnology. Vol.:1. No: 4. 201-205p. 2014

RODRÍGUEZ, I. Conocimiento indígena vs. Científico: el conflicto por el uso del fuego en el Parque Nacional Canaima, Venezuela. Interciencia. Vol.: 29: 121129pp. 2004.

RODRÍGUEZ, I. Pemón Perspectives of Fire Management in Canaima National Park, Southeastern Venezuela. Human Ecology. Vol.:35: 331-343 pp. 2007.

RODRÍGUEZ, I. Y SLETTO, B. Apök hace feliz a Patá. Desafíos y sugerencias para una gestión intercultural del fuego en la Gran Sabana. Antropológica.Vol.: 53:111p. 2009.

ROJAS, M. I. E ALFARO, E.J. Influencia del océano Atlántico tropical sobre el comportamento de la primera parte de la estación lluviosa em Venezuela. Top. Meteor. Oceano. Vol: 2. No 2. 88-92 p. 2000. 
ROUSE, J.W.; HAAS, R.H.; SCHELL, J.A.; DEERING, D.W. Monitoring vegetation systems in the great plains with ERTS. In: Third ERTS Symposium, Proceedings, NASA SP-351, NASA. Washington, DC. Vol: 1: 309-317pp.1973.

RULL, V. Successional patterns of the Gran Sabana (southeastern Venezuela) vegetation during the last 5.000 years, and its responses to climatic fluctuations and fire. Journal of Biogeography. Vol.: 19:329- 338pp. 1992.

RULL, V. A palynological record of a secondary succession after fire in the Gran Sabana, Venezuela. Journal of Quaternary Science. Vol.:14:137-152pp. 1999.

RULL, V. Biogeografía histórica de las Tierras Altas de Guayana y origen de la biodiversidad neotropical. Orsis. Vol.:19:37-48pp. 2004.

SCHUBERT, C.; BRICEÑO, H. O. e FRITZ, P. Paleoenvironmental aspects of the caroní- Paragua river basin southeastern Venezuela. Interciencia. Vol.:11: 278289pp. 1986.

TORRES, I. N. e MARTIN, D. D. Informe final de la evaluación del Parque Nacional Canaima, Venezuela, como Sitio de Patrimonio Natural de la Humanidad. Venezuela: Caracas. 127 pp. 2007.

TUDARE, J.L. MILLANO E TREJO, F. J. PAREDES. Influencia del fenómeno El niño/Oscilación del Sur (ENSO) sobre la precipitación en la cuenca del Río Caroní, Estado Bolívar, Venezuela. Agrollania. Vol: 10. 13 p.2013.

XAVIER-DA-SILVA, J e CARVALHO, L.M. Sistemas de informação geográfica: uma proposta metodológica. IV Conferência Lationoamericana sobre sistemas de informação geográfica. $2^{\circ}$ Simposio Brasileiro de Geoprocessamento, São Paulo. 1993. 